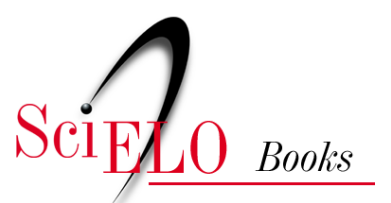

\title{
Capítulo 6. Reflexões acerca do mundo cultural e do comportamento reprodutivo dos Kamaiurá ontem e hoje
}

\author{
Carmen Junqueira \\ Cândido P. F. de Camargo \\ Heloísa Pagliaro
}

JUNQUEIRA, C., CAMARGO, C.P,F., and PAGLIARO, H. Reflexões acerca do mundo cultural e do comportamento reprodutivo dos Kamaiurá ontem e hoje. In: PAGLIARO, H., AZEVEDO, MM., and SANTOS, RV., comps. Demografia dos povos indígenas no Brasil [online]. Rio de Janeiro: Editora FIOCRUZ, 2005, pp. 119-134. Saúde dos Povos Índigenas collection. ISBN: 978-85-7541-254-1. https://doi.org/10.7476/9788575412541.0007.

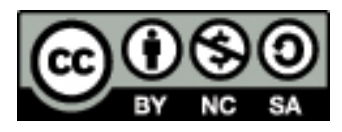

All the contents of this work, except where otherwise noted, is licensed under a Creative Commons Attribution-Non Commercial-ShareAlike 3.0 Unported.

Todo o conteúdo deste trabalho, exceto quando houver ressalva, é publicado sob a licença Creative Commons Atribuição - Uso Não Comercial - Partilha nos Mesmos Termos 3.0 Não adaptada. 


\section{Reflexões Acerca do Mundo Cultural e do Comportamento Reprodutivo dos Kamaiurá Ontem e Hoje}

Cândido Procópio F. de Camargo, Carmen Junqueira e Heloísa Pagliaro

\section{Preâmbulo}

Em 1971, Camargo e Junqueira escreveram um texto intitulado 'Análise da Fecundidade Kamaiurá' que não chegou a ser publicado na íntegra, ainda que muitos de seus resultados e discussões tenham sido recuperados no livro 'Os Índios do Ipavu' (Junqueira, 1978). Cândido Procópio Ferreira de Camargo foi sociólogo e demógrafo de grande expressão, tendo integrado o Centro de Estudos de Dinâmica Populacional da Universidade de São Paulo (Cedip) e posteriormente o Centro Brasileiro de Análise e Planejamento (Cebrap). Falecido em 1987, sua colaboração com Junqueira foi uma incursão pioneira no campo da demografia indígena no Brasil, sobretudo pela reflexão acerca das variáveis intermediárias que influenciam a fecundidade propostas por Davis e Blake.

Este capítulo encontra-se estruturado em duas partes. Na primeira está reproduzido o texto original de Camargo e Junqueira. Optou-se por mantê-lo na forma concebida à época em que foi escrito, inclusive no tocante à bibliografia utilizada. Na segunda parte, são apresentadas por Junqueira e Pagliaro breves análises com base em dados coletados em uma viagem recente (2003). Menos do que produzir uma análise detalhada, o intuito dessa revisita aos Kamaiurá foi o de fornecer um retrato recente, três décadas depois, de algumas mudanças culturais e demográficas.

PARTE I

\section{Análise da fecundidade Kamaiurá}

O inédito crescimento populacional contemporâneo ocasionou a recente expansão dos estudos demográficos. Análises de censos e estudos empíricos por amostragem multiplicaram-se nos últimos 30 anos. Ambiciosos projetos de planificação familiar procuraram afastar o espectro das previsões malthusianas. 
A atual expansão populacional, fundamentalmente devida ao crescimento demográfico dos países subdesenvolvidos, coloca de modo agudo problemas de caráter econômico, social e político.

A pressão do aumento populacional traz conseqüências políticas internas em vários países e redefine a distribuição de etnias e culturas em perspectiva internacional. Implica, igualmente, problemas econômicos, interpretados de forma catastrófica pelos economistas de orientação neo-malthusiana (Singer, 1970).

Os trabalhos de campo em demografia, as interpretações teóricas e as análises versando sobre o relacionamento entre as variáveis populacionais e as de natureza econômica e social estão geralmente baseadas em uma concepção teórica que se convencionou chamar de transição demográfica. Grande número de trabalhos científicos recorre a esta teoria de modo explícito. Constitui-se no arcabouço explicativo mais genérico para a compreensão da dinâmica das populações modernas. Mesmo quando não haja explicitação formal, os pressupostos da teoria da transição demográfica inspiram a seleção de dados e o delineamento da maioria das pesquisas demográficas contemporâneas.

Seria impróprio esboçar no presente artigo uma crítica epistemológica da teoria da transição demográfica, que apresenta, inegavelmente, algumas vantagens operacionais. Queremos apenas, ao descrever a dinâmica populacional dos Kamaiurá, especialmente seu comportamento reprodutivo, pôr em questão certos abusos de generalização, bem como mostrar a irrelevância, no caso concreto, de categorias dicotômicas do tipo tradicional versus moderno, incluídas nos fundamentos da teoria da transição demográfica.

De forma bastante sucinta, o esquema da teoria da transição demográfica descreve a passagem de altos níveis de natalidade e de mortalidade, para níveis baixos e controlados, num período transitório em que o declínio da mortalidade antecede o da natalidade, gerando rápido crescimento populacional nas sociedades pré-industriais quando se industrializam (Coale G Hoover, 1958).

A ampla utilização, por vezes implícita, da teoria da transição demográfica, com a finalidade de descrever e interpretar tendências populacionais contemporâneas, tem envolvido generalizações nem sempre consubstanciadas em fatos. O exemplo da pequena população Kamaiurá é bastante ilustrativo (sobretudo se o comparamos com os padrões predominantes de fecundidade nas populações caboclas circunvizinhas).

Visando a facilitar o confronto entre a perspectiva teórica da teoria da transição demográfica e os fatos populacionais observados no grupo Kamaiurá, assume-se a proposta de ressaltar alguns aspectos particularmente contrastantes. Neste sentido, pode-se dizer que a teoria da transição demográfica supõe que: $1^{\circledR}$ ) os povos pré-industriais têm alta fecundidade, que é regulada somente por normas sociais que afetam - de modo não intencional - as chamadas variáveis intermediárias 
de Davis e Blake (Freedman, 1963); $2^{\circ}$ ) os povos pré-industriais não definem de maneira expressa e intencional o número de filhos desejados, tendendo a perceber como uma fatalidade o tamanho normalmente alcançado por suas famílias; $3^{\circ}$ ) as culturas dos povos pré-industriais não explicitam valores racionais, colocados como fins ou como meios, na justificativa do número de filhos considerados ideais (tamanho ideal da família).

\section{O grupo estudado}

Na região dos formadores do rio Xingu vivem os índios Kamaiurá, de filiação lingüística Tupi, em profunda interação com outros grupos tribais, mas resguardados de contato regular com a sociedade brasileira. Os fatores que mais favoreceram tal isolamento parecem ter sido as barreiras naturais que circundam a região, a presença de tribos indígenas agressivas e o relativo desinteresse econômico da sociedade nacional por aquelas terras. Embora, no momento, os elementos que garantem o isolamento estejam ameaçados de perto tanto pela abertura de rodovias, como pela 'neutralização' de tribos hostis e pelo vivo interesse por terras indígenas, vivem ainda os Kamaiurá como um grupo que se distingue da chamada 'civilização ocidental'.

A história de seu contato com representantes dessa civilização remonta a 1884, com a expedição de Karl von den Steinen. Daí por diante, várias expedições penetraram na região e estabeleceram contatos intermitentes e de curta duração com o índio alto-xinguano.

Um canal de contato mais regular, se bem que indireto, estabeleceu-se ainda em 1884, com a aproximação dos índios Bakairi, dos rios Novo e Paranatinga, aos do rio Batovi. Esse encontro, que mais tarde provocou o deslocamento dos Bakairi dos formadores do Xingu para o Paranatinga, propiciou a entrada de objetos da civilização, bem como de doenças na região. Porém, somente na década de 1940 é que os alto-xinguanos estabeleceriam contato mais estreito com a sociedade nacional.

Em 1942, com a criação do órgão federal Fundação Brasil Central, iniciase a abertura de estradas e o estabelecimento de acampamentos na área. A coluna de homens responsáveis por essa penetração, cognominada Expedição RoncadorXingu, alcaṛça em 1946, a zona dos formadores do Xingu e funda, num de seus tributários, o ribeirão Jacaré, um posto com o mesmo nome. Permanecem nesse posto e noutro - Diawarum - localizado mais ao norte, os irmãos Villas Bôas, procurando proteger os índios de maneira mais efetiva. Os resultados das experiências do Serviço de Proteção aos Índios, em algumas dezenas de anos de atividade indigenista, mostravam claramente que não bastava a instalação 
de postos assistenciais para garantir a sobrevivência do índio. O processo de expansão da sociedade brasileira e o avanço violento de suas frentes pioneiras, quando não exterminavam sumariamente o índio, colocavam-no frente a uma situação de contato a cujo impacto não podia resistir por carência de recursos biológicos e culturais.

A primeira etapa da tarefa, a ser realizada pelos irmãos Villas Bôas, era garantir ao alto-xinguano, de maneira efetiva, a posse da terra, não permitindo que o território sofresse redução capaz de colocar em perigo o funcionamento de sua economia tradicional. E não há dúvida de que se não fossem adotadas medidas severas a esse respeito, de pouco valeria a instalação de postos na região. Prova disso foi dada poucos anos após a penetração da Expedição Roncador-Xingu, na área que, apesar de economicamente marginal, ganhou destaque no cenário brasileiro. Não tardou que a nova região desbravada viesse a ser alvo de interesses imobiliários. Sob as vistas da Fundação Brasil Central, a terra passou a ser retalhada e vendida a particulares. Somente a reação enérgica dos líderes da extinta expedição e do Serviço de Proteção aos Índios conseguiu sustar a comercialização das terras indígenas. Finalmente, em 1961, é que se logrou alcançar uma proteção mais definitiva desse território, com a criação do Parque Nacional do Xingu.

Contando com uma área de $22.000 \mathrm{~km}^{2}$, o Parque Nacional do Xingu objetiva assegurar a sobrevivência dos grupos indígenas da área e preservar os recursos de flora e fauna que constituíam reservas destinadas a estudos científicos.

Em linhas gerais, duas preocupações básicas orientam hoje, como na época de sua fundação, as atividades do Parque. De um lado, procura ele garantir a sobrevivência das populações indígenas mediante a adoção de medidas médicopreventivas e curativas. Nesse sentido, interfere, de forma planejada, inclusive na esfera nativa de produção de alimentos, visando ao enriquecimento da dieta tradicional. Exerce ainda controle sobre os contatos entre índios e civilizados, tendo em mira impedir a entrada de doenças contagiosas nas aldeias. A longo prazo, empenha-se em preparar o índio para que se mantenha autônomo como povo, quando, num futuro não determinado, entrar em contato mais direto com a sociedade brasileira. Inovações são, para esse fim, introduzidas lentamente ao mesmo tempo em que se procura preservar a coesão social de cada um dos grupos nativos.

Dentro dessa linha de pensamento, o Parque estimula a realização das principais cerimônias nativas e prestigia os líderes das aldeias que detêm controle efetivo sobre o comportamento dos índios. Os dirigentes do Parque. concomitantemente ao encaminhamento das atividades em direção aos objetivos previamente estabelecidos, estão também conscientes do perigo que uma mudança provocada pode acarretar, vale dizer, a desorganização e a perda da identidade cultural dos grupos. 
A realização dessas tarefas exige por parte dos dirigentes do Parque um controle muito grande de todas as situações que envolvam não só a introdução de novos artigos na área, mas também das relações entre civilizados e índios. O sucesso desse tipo novo de empreendimento reside na identificação e intervenção rápidas de todo processo que possa vir a desencadear mudanças desorganizatórias nas aldeias. Quanto menores as interferências na vida do índio que escapam ao controle do Parque, maiores serão as garantias da obtenção dos resultados objetivados.

Os contatos entre índios e civilizados ocorrem dentro do próprio Parque, uma vez que este existe como verdadeira 'reserva' onde é controlada a entrada e a saída das pessoas. Ainda que seja difícil um total controle sobre o comportamento dos índios, e possam ocorrer saídas irregulares, que aliás são raras, o isolamento da região desestimula as transgressões. Ao lado disso, o Parque, como único fornecedor regular de bens vindos da 'civilização', está em condições de persuadir o índio a permanecer dentro de seus limites geográficos.

Dentro do Parque, o índio tem contatos ocasionais com visitantes ou pesquisadores e contatos mais freqüentes com o pessoal da Base Aérea da Força Aérea Brasileira, localizada dentro dos limites do Parque. Por força dessa situação de contato controlado, a cultura dos grupos tribais da região, e entre eles a dos Kamaiurá, mantém-se relativamente inalterada, operando com determinantes basicamente tradicionais e, portanto, tribais.

Os dados apresentados aqui foram retirados de pesquisa mais ampla realizada na área, desde 1968. Nessa pesquisa procurou-se explicar e analisar o projeto de vida Kamaiurá. Numa análise preliminar do material, defrontou-se com elementos que mostravam ser diferente o comportamento fértil do grupo em relação ao comportamento de outras comunidades tribais do Brasil e de grupos vizinhos civilizados, constituídos em sua maioria por frente cabocla. E mais ainda, seu comportamento fértil exibia alguns pontos de contato com o das sociedades modernas industrializadas. $O$ fato mereceu grande atenção por ser o comportamento fértil Kamaiurá derivado de elaboração cultural interna e não influência da sociedade brasileira.

\section{Dados demográficos}

Os,dados de natureza demográfica foram coligidos na aldeia Kamaiurá mediante entrevistas, obtendo-se informações relativas ao número e à composição por sexo e idade da população. A especificação da idade foi aproximada, não havendo meios seguros para determinar com precisão o ano de nascimento dos indivíduos, especialmente dos de mais de 30 anos. Optou-se pela inclusão dos indivíduos em faixas de idade a fim de minimizar as possibilidades de erro. 
As pirâmides de idade apresentadas nas Figuras 1 e 2 revelam as drásticas alterações da situação de vida da população em 1949 em comparação com sua situação em 1971, ocasião da pesquisa de campo. A Figura 1, de Galvão (1949), revela uma composição populacional caracterizada por pequena porcentagem de pessoas com menos de 14 anos em razão dos altos índices de mortalidade infantil e de mortalidade de jovens, refletindo a fase final de um longo e doloroso processo de depopulação. Iniciando-se em 1946 uma política mais racional e humana, sob a liderança dos irmãos Villas Bôas, em relação a vários grupos indígenas na região do Xingu, inclusive os Kamaiurá, verifica-se o crescimento populacional e a natural ampliação das faixas etárias mais jovens na população. Nota-se, também, os efeitos, sobre a população de 15 a 29 anos, de uma epidemia de sarampo que acometeu cerca de 600 índios do Alto Xingu, em 1954, matando 15 kamaiurá (Motta, 1954).

Figura 1 - Pirâmide etária dos Kamaiurá, 1949

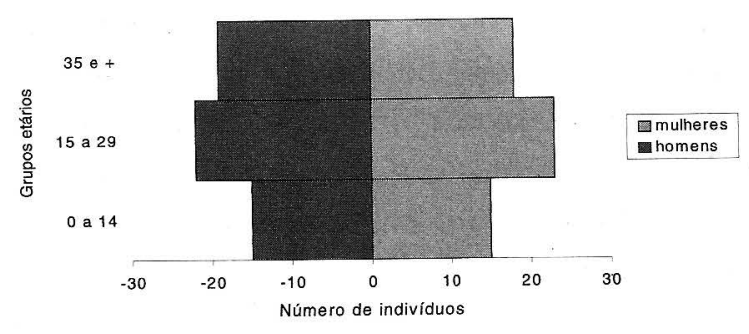

Figura 2 - Pirâmide etária dos Kamaiurá, 1971

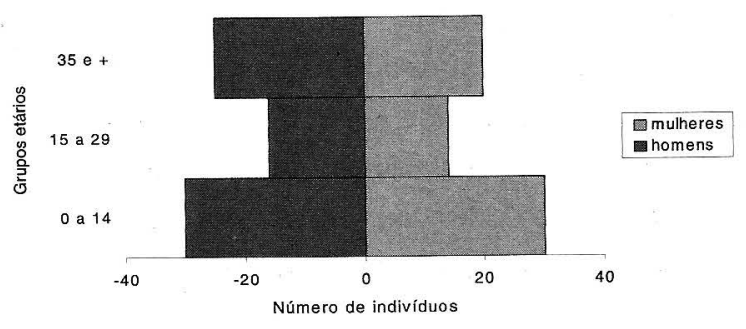

A comparação dessas pirâmides evidencia mudanças acentuadas nas condiçōes de vida do grupo nos últimos vinte anos. Realmente, o Parque Nacional do Xingu veio criar condições que impediram o impacto mais agressivo da sociedade brasileira. Persistindo muitos dos valores da cultura grupal, desenvolveu-se também o crescimento da população em virtude da adoção de medidas sanitárias que vieram a reduzir consideravelmente a mortalidade infantil.

A Tabela 1 apresenta o número de mulheres não-solteiras da aldeia e a média de filhos tidos, vivos e mortos até 1971. A média de filhos vivos por mulher, em grande maioria ainda em período reprodutivo, é de 2,4. Considerando-se todos 
os nascimentos vivos, a média é de 3,7 filhos por mulher, tendo a fecundidade acumulada até o final do período reprodutivo variado entre 3,5 e 7 filhos para as seis mulheres com 40 anos ou mais. A média de filhos mortos de todas as mulheres é de 1,3 e a das mulheres de 40 ou mais anos variou entre 1,5 e 4 filhos.

Esses dados revelam um padrão de fecundidade certamente muito inferior às possibilidades biológicas de reprodução do grupo Kamaiurá. Evidentemente, os baixos níveis de fecundidade, inferiores aos das populações caboclas brasileiras, indicam a presença de normas sociais que afetam as chamadas variáveis intermediárias de Davis e Blake, que influenciam a fecundidade (Freedman, 1963).

Tabela 1 - Mulheres kamaiurá maiores de 15 anos de idade e médias de filhos tidos, vivos e mortos, até 1971

\begin{tabular}{ccccc}
\hline $\begin{array}{c}\text { Grupos de idades } \\
\text { aproximadas }\end{array}$ & Mulheres não-solteiras & Média de filhos vivos & Média de filhos mortos & Média de filhos tidos* \\
\hline 15 a 19 & 1 & - & - & - \\
20 a 24 & 5 & 1,8 & 0,2 & 2,0 \\
25 a 29 & 5 & 1,8 & 0,6 & 2,4 \\
30 a 34 & 3 & 3,7 & 1,0 & 4,7 \\
35 a 39 & 9 & 3,2 & 1,7 & 4,9 \\
40 a 44 & 1 & 3,0 & 4,0 & 7,0 \\
45 a 49 & 2 & 2,0 & 1,5 & 3,5 \\
50 a 54 & 3 & 1,7 & 3,0 & 4,7 \\
\hline Total & 29 & 2,4 & 1,3 & 3,7 \\
\hline
\end{tabular}

*Excluídos os sacrificados por infanticídio.

Fonte: Pesquisa de campo, 1971.

As variáveis intermediárias são aquelas que afetam diretamente a fecundidade de uma população. As normas e valores sociais afetam a fecundidade necessariamente, por meio da atuação das variáveis intermediárias. Davis e Blake classificaram os seguintes fatores como constitutivos das variáveis intermediárias: fatores relativos à formação e à dissolução de uniões; fatores relativos à relação sexual na união; fatores relativos à exposição à concepção; fatores relativos à gestação e ao parto.

Não é particularmente significativo no estudo do comportamento reprodutivo da população Kamaiurá apenas a análise de normas e valores que afetam as variáveis intermediárias e determinam de maneira não intencional um certo padrão de fecundidade. Mais relevante é a existência de valores precisos quanto ao número ideal de filhos e a disposição - com os recursos técnicos disponíveis de limitar a prole ao número desejado. 
Para fins da presente análise, faz-se a distinção entre as normas e valores que afetam a fecundidade de modo não intencional e os valores conscientes sobre o tamanho da família e o número ideal de filhos.

\section{Normas e valores que afetam de modo não intencional a fecundidade}

\section{Fatores relativos à formação da união}

Há na cultura Kamaiurá uma expectativa generalizada de que todas as pessoas devem se casar. O casamento, além das funções de procriação e as de natureza sexual, torna-se igualmente necessário por razões econômicas, decorrentes da divisão social do trabalho. Salvo uma jovem recém-saída da reclusão e uma separada, em 1971 não havia nenhuma mulher, em idade fértil, não casada na aldeia.

O casamento se efetua, para as mulheres, logo após o início de seu período reprodutivo, e o tempo de reclusão após a primeira menstruação prolonga-se até o máximo de um ano. Cessando a reclusão, ocorrem imediatamente os casamentos, em geral anteriormente combinados.

A ruptura da união, conseqüente da separação do casal, não impede a contratação imediata de um novo casamento. A morte de um cônjuge, entretanto, obriga o sobrevivente a um período considerado de 'luto', cuja duração é variada, em que não pode se casar novamente.

De modo geral, pode-se considerar que as normas relativas à formação da união tenderiam a favorecer uma alta fecundidade, quer pelo início precoce do matrimônio, quer pela facilidade na contratação de novo casamento. Em relação às normas de casamento há de se ter em conta também a liberdade de relações extraconjugais, que representa uma modalidade restrita, mas relativamente difundida de relacionamento sexual. Normalmente, formam-se casais de namorados, parceiros temporariamente estáveis, cujo grau de legitimação é muito inferior ao do casamento. Esse tipo de união é muito menos fecunda do que o casamento formal, como se verá a seguir.

Fatores relativos à relação sexual

Existem restrições que limitam as relações sexuais em certas ocasiões: quanto aos homens, ocorrem restrições ao relacionamento sexual dos pajés durante seu período de iniciação e dos lutadores durante o período das competições festivas; no tocante às mulheres, prevê-se um período de abstinência sexual que, idealmente, deveria perdurar durante um ano após o parto; interessante observar que a cultura 
Kamaiurá não considera a relação sexual como uma obrigação estrita ligada aos papéis de mulher casada. Supõe-se a anuência voluntária da mulher, não havendo expectativa de formas de constrangimento que a obriguem a uma relação momentaneamente não desejada.

\section{Fatores que afetam a concepção}

Como as crianças são amamentadas por período variado de tempo, no entanto, geralmente bastante longo, chegando até três anos, a fecundabilidade das mulheres diminui consideravelmente nesse espaço de tempo.

\section{Normas e valores que afetam de modo intencional a fecundidade}

Habitualmente as decisões relativas às conseqüências reprodutivas do ato sexual e à continuidade das gestações decorrem de intenções conscientes a respeito do tamanho da família e do desejo de ter ou não um filho. Os Kamaiurá afirmam ter o conhecimento de ervas capazes de evitar a concepção e que seriam propriamente anticoncepcionais. As análises farmacológicas realizadas até o momento não foram suficientes para comprovar a veracidade dessa alegação.

Observa-se que acreditam igualmente na propriedade que têm algumas ervas de facilitar a fecundação.

Quanto às variáveis relativas ao desenvolvimento da gestação, afirmam os Kamaiurá possuir remédios capazes de provocar o abortamento. Quer por intermédio de processos mecânicos, quer por meio de ervas, cuja eficácia farmacológica não é controlada, as mulheres praticam efetivamente o abortamento.

Em algumas situações sociais a cultura Kamaiurá legitima o abortamento. Usualmente, o status da mulher constitui o fundamento para a decisão de abortar. As mulheres sem marido ou cujo marido tenha estado ausente por um período longo de tempo recorrem a práticas abortivas. O padrão de liberdade sexual extraconjugal pode ocasionar concepção indesejável, que é igualmente interrompida.

Observe-se que o infanticídio como forma eticamente aceita de impedir a sobrevivêncịa do recém-nascido justifica-se no caso do nascimento de gêmeos, de crianças defeituosas e, eventualmente, nas situações de status análogas às que levam ao abortamento provocado. Importante considerar que as práticas abortivas são também utilizadas como uma maneira deliberada de planejar o tamanho da família e evitar um nascimento indesejado. 
A Tabela 2 revela o número ideal de filhos por sexo e idade dos entrevistados. As perguntas formuladas foram: "Quantos filhos é bonito ter?" e "Quantos filhos gostaria de ter?", ou indagações semelhantes que visavam esclarecer ao entrevistado o sentido da questão.

Inicialmente, a pesquisa permitiu verificar que a idéia de um tamanho 'bonito' e conveniente de família não era estranha ao universo cultural do grupo estudado. $\mathrm{O}$ tamanho ideal apresentado estava longe das potencialidades biológicas e indicava uma dimensão não muito grande de família.

Entre as gerações, as diferenças relativas ao tamanho ideal de família seriam devidas, provavelmente, à acentuada diminuição da mortalidade infantil e da mortalidade entre os jovens, levando as mulheres das gerações que iniciam seu período reprodutivo a redefinirem o número desejado de filhos de modo a manterem a mesma família relativamente pequena da tradição Kamaiurá.

Tabela 2 - Número de mulheres e homens entrevistados, médias de filhos vivos, mortos e idealizados

\begin{tabular}{|c|c|c|c|c|c|c|c|c|}
\hline $\begin{array}{l}\text { Grupos de } \\
\text { idades } \\
\text { aproximadas }\end{array}$ & $\begin{array}{c}\text { N. de } \\
\text { mulheres } \\
\text { entrevistadas }\end{array}$ & $\begin{array}{l}\text { Média de } \\
\text { filhos vivos }\end{array}$ & $\begin{array}{l}\text { Média de filhos } \\
\text { mortos }\end{array}$ & $\begin{array}{l}\text { Média de } \\
\text { filhos } \\
\text { idealizados }\end{array}$ & $\begin{array}{l}\text { N. de homens } \\
\text { entrevistados }\end{array}$ & $\begin{array}{l}\text { Média de } \\
\text { filhos vivos }\end{array}$ & $\begin{array}{c}\text { Média de } \\
\text { filhos mortos }\end{array}$ & $\begin{array}{l}\text { Média de } \\
\text { filhos } \\
\text { idealizados }\end{array}$ \\
\hline 15 a 19 & 2 & - & - & 2,0 & - & - & - & - \\
\hline 25 a 29 & 2 & 2,5 & 1,0 & 2,8 & 1 & 2.0 & - & 2,5 \\
\hline 30 a 34 & 1 & 6,0 & 1,0 & 10,0 & 2 & 2,0 & 1,0 & 3,3 \\
\hline 35 a 39 & 4 & 2,5 & 1,0 & 6,4 & 1 & 2,0 & 2,0 & 2,0 \\
\hline 45 a 49 & - & - & - & - & 1 & 4,0 & 2,0 & 7,5 \\
\hline 50 a 54 & 3 & 1,7 & 3,0 & 5,3 & - & - & - & - \\
\hline Total & 12 & 2,2 & 1,3 & 5,1 & 5 & 2.4 & 1,0 & 3.7 \\
\hline
\end{tabular}

Fonte: Pesquisa de campo, 1971.

A Tabela 3, construída por Ribeiro (1970) com dados de 1954, mostra para os Kuikuro, população culturalmente análoga à Kamaiurá, índices de fecundidade semelhantes aos das gerações mais velhas do grupo estudado. A diferença evidente entre esta Tabela e a Tabela 2 diz respeito aos níveis de mortalidade. A taxa de mortalidade Kamaiurá decresceu rapidamente nas últimas dủas décadas. Presume-se que provavelmente esta alteração da dinâmica populacional veio ocasionar uma diminuição no número de filhos necessários para conseguir na sociedade Kamaiurá o mesmo padrão de família que é funcional ao seu modo de produção e à sua cultura. 
Tabela 3 - Número de mulheres, partos, nascimentos vivos, filhos mortos e sobreviventes

\begin{tabular}{ccccc}
\hline Partos & Mães & Nascimentos & Mortes & Sobreviventes \\
\hline 1 & 6 & 6 & 2 & 4 \\
2 & 2 & 4 & 2 & 2 \\
3 & 5 & 15 & 7 & 8 \\
4 & 3 & 12 & 5 & 7 \\
5 & 4 & 20 & 12 & 8 \\
6 & 1 & 6 & 5 & 1 \\
7 & 4 & 28 & 20 & 8 \\
8 & - & - & - & - \\
9 & 2 & 18 & 10 & 8 \\
\hline Totais & 27 & 109 & 63 & 46 \\
\hline
\end{tabular}

Fonte: Ribeiro, 1970.

$\mathrm{Na}$ interpretação do tamanho ideal de família, convém observar que as respostas fornecidas pelos informantes parecem indicar níveis diferentes de concreção.

O nível mais genérico e afastado da situação pessoal do entrevistado é aquele no qual se considerava bom e conveniente um número relativamente grande de filhos (entre 5 e 10); o outro, mais específico, é o nível que implicava a definição de intenções pessoais do entrevistado, no qual o número de filhos desejado girava entre 2 e 4.

O aspecto particularmente significativo da dinâmica populacional Kamaiurá é concernente ao nível de plena racionalidade com que se entende o processo reprodutivo. Esta racionalidade, que a teoria da transição demográfica supõe emergir após um processo histórico determinado, encontra-se realizada sem outras interferências culturais na tradição Kamaiurá.

A análise das motivações acerca do tamanho da família e dos motivos que justificariam sua ampliação ou diminuição, deixa transparecer um estilo de controle racional que nos surpreende por sua 'modernidade'. Assim, o desejável aumento da família liga-se, especialmente em relação aos homens com funções de liderança, à idéia de que a expansão demográfica Kamaiurá é condição de sobrevivência do grupo e de realização mais completa de suas aspirações culturais. A família grande é igualmente justificada em termos dos papéis de proteção e segurança que os filhos poderiam representar em relação aos pais. 
Por outro lado, racionalidade paralela encontra-se nas justificativas referentes a um ideal de família bastante reduzida. "Os filhos gastam muita comida" e "dão muito trabalho" constituem o centro da argumentação de natureza econômica que fundamenta, aos olhos da cultura Kamaiurá, a opção por uma família pequena.

Encontramo-nos, pois, perante uma atitude racional e 'moderna' que escapa inteiramente ao evolver histórico previsto na teoria da transição demográfica. Na visão Kamaiurá da família não ocorre uma concepção fatalista ou a inércia do peso de uma tradição estática, mas um projeto perfeitamente consciente de que o tamanho da família constitui uma esfera de decisão livre e racional. Nem a frente cabocla brasileira, nem os contatos ocorridos no Parque explicariam as atitudes e valores dos Kamaiurá sobre o comportamento reprodutivo. Seria interessante comparar as concepções dos setores rurais brasileiros, determinadas por suas funções na divisão social do trabalho da nação com a visão do mundo Kamaiurá, muito mais livre, e que define seus objetivos tomando por base uma visão globalizante de seus próprios interesses e do patrimônio cultural que lhe cabe usufruir e preservar.

\section{PARTE II}

\section{Revisitando os Kamaiurá}

Cerca de trinta anos depois da pesquisa de Candido Procópio Ferreira de Camargo e Carmen Junqueira, que serviu de base para o artigo 'Análise da fecundidade Kamaiurá', revisitou-se a aldeia de Ipavu a fim de estudar as mudanças ocorridas na relação que os índios mantinham com o modo de vida tradicional e avaliar alguns aspectos do seu padrão reprodutivo. Partiu-se do pressuposto de que nessas três décadas deveria ter ocorrido a reelaboração de aspectos da sua tradição, que permitisse melhor enfrentar as novas condições criadas pela expansão da agropecuária no Centro-Oeste brasileiro, inclusive o surgimento de cidades nas adjacências do Parque Indígena do Xingu.

As informações que aqui são apresentadas resultaram da viagem realizada à área, entre os dias 8 e 21 de julho de 2003. O tempo relativamente curto da observação de campo permitiu o registro e a análise preliminar de inovações introduzidas na vida da aldeia e o levantamento de algumas informações demográficas, completadas com dados do arquivo do programa de saúde da Universidade Federal de São Paulo (Unifesp), permitindo traçar em linhas gerais o sentido de alguns processos em curso. 
Do ponto de vista cultural, embora o ritmo de vida pouco tenha se alterado, inovações recentes foram incorporadas ao dia-a-dia da aldeia. É o caso, por exemplo, do conjunto de poço, caixa d 'água e bomba movida a energia solar, que leva água a torneiras instaladas no fundo das casas, facilitando tarefas domésticas e melhorando as condições de saúde de modo geral. O uso regular de caminhão, trator, gerador, motores de popa, aparelhos de televisão e rádio transmissor acarretou maior mobilidade, redução do tempo de trabalho e maior familiaridade com a vida urbana, seja pelas viagens mais constantes até cidades vizinhas, seja pelas imagens fornecidas pela televisão. A manutenção desses equipamentos é um dos desafios que os Kamaiurá enfrentam, pois a necessidade de moeda ganhou espaço. Sabem que sem dinheiro não é possível comprar gasolina, pagar o conserto dos motores e adquirir uma série de outros artigos que já fazem parte do rol das novas necessidades.

Quem garante o pagamento das despesas da comunidade é a Associação Mavutsinin, cujos recursos vêm principalmente da venda de artesanato e doações eventuais. Mas os propósitos da Associação são bem mais amplos, estendendo-se à elaboração e execução de projetos na área social e cultural. Na época da pesquisa, a Associação coordenava e executava três projetos, dentre eles o da Escola Mawaiaka.

Os objetivos da escola são: preservar e resgatar a cultura Kamaiurá e capacitar jovens e crianças no uso dos conhecimentos não índios. Deve-se aos velhos a idéia de criar uma escola que atendesse diretamente aos interesses dos índios. Os alunos têm aulas de mitologia Kamaiurá, luta huka huka, música tradicional, pintura corporal, artesanato e língua Kamaiurá (escrita e leitura). Mesmo as disciplinas básicas do Ensino Fundamental - português, matemática, geografia e história - são introduzidas de modo diferenciado, apoiadas no conhecimento dos velhos e nas atividades cotidianas. Desse modo, a geografia parte da descrição e classificação dos espaços indígenas; a história, dos deslocamentos da aldeia no decorrer dos tempos; o ensino do português volta-se, num primeiro momento, à compreensão da língua falada; e a matemática, à habilidade de contar e usar dinheiro. O projeto acumula resultados positivos na dinamização de conteúdos culturais previstos na programação curricular. Aumentou também a compreensão da língua portuguesa, e vários jovens já estão alfabetizados. O desafio agora é progredir nạ leitura e escrita Kamaiurá, que vêm sendo retomadas após terem sido definidas as regras para a escrita.

De modo geral, a continuidade cultural que as gerações mais velhas querem assegurar acaba sendo mantida ao longo de sucessivas metamorfoses e agregações. Ilustra bem essa afirmação o que se observou e registrou no diário de campo: 
Olhando a aldeia como um todo as coisas parecem embaralhadas, principalmente a partir do entardecer quando diferentes comportamentos se cruzam: alguns jovens estacionam suas bicicletas em frente à casa das flautas e trajando tênis e bermudões conversam animadamente; no pátio central garotos e rapazes jogam animados uma partida de futebol; atrás da casa das flautas, um outro time formado por moças disputa uma outra partida. Em algumas tardes é possível ainda ver um time mirim de meninos e meninas nos espaços que restam. Quando a noite chega, é a vez do grupo de crianças se reunir no pátio para ensaiar cantigas tradicionais que aprendem na escola, enquanto uns poucos meninos treinam a luta huka huka. Quando tudo escurece, pode ter início numa das casas uma sessão de vídeo de uma festa do kuarup, exibido quase todas as noites e, em seguida, ouve-se um CD com músicas cerimoniais Kamaiurá e cantos em língua Jê. O som se propaga pelas casas vizinhas e se mistura com as melodias de Kelly Key, Rouge e conjuntos americanos modernos, rodadas num conjunto de som poderoso. Se algum aparelho de televisão estiver funcionando, chega a hora da novela. No dia seguinte, um conjunto de flautas uruá vai de casa em casa, enchendo a aldeia da atmosfera de outros tempos. Tudo parece indicar que novidades modernas chegam e se acomodam ao lado dos costumes antigos, como se sempre tivesse sido assim.

Do ponto de vista demográfico, observou-se um vigoroso aumento populacional nesses 32 anos. Em 1971, a população total kamaiurá era de 131 habitantes (Junqueira, 1978). Em 2003, viviam em duas aldeias, em razão de uma cisão do grupo em meados da década de 80, perfazendo um total de 378 indivíduos. Nesse período, o crescimento médio anual da população foi de $3 \%$ ao ano, e estaria acompanhando a tendência observada em outras populações indígenas do PIX, como os Waurá, também moradores do Alto Xingu, que cresceram 4,8\% entre 1970 e 1999.

As pirâmides etárias de 1971 e 2003, apresentadas em números absolutos, nas Figuras 3 e 4, demonstram significativas mudanças na estrutura populacional, sendo notória a aquisição de uma maior regularidade no contorno da pirâmide de 2003, a ampliação do número de crianças, jovens e indivíduos maiores de 55 anos, indicando aumento da sobrevivência da população em geral.

A Tabela 4 mostra o número de mulheres não solteiras, com idades entre 15 e 54 anos, seus filhos vivos e mortos em 2003 e indicadores da fecundidade acumulada dessas mulheres. Mudanças no tamanho de família podem ser observadás mediante tais dados, tendo o número médio de filhos vivos das mulheres não solteiras aumentado de 2,4 para 4,0. Considerando-se os filhos tidos, não computados os sacrificados por infanticídio, a média de filhos por mulher variou de 3,7 para 4,3, tendo a média de filhos mortos diminuído de 1,3 para 0,3 por mulher. 
Figura 3 - Pirâmide etária dos Kamaiurá, em grupos qüinqüenais de idade, 1971

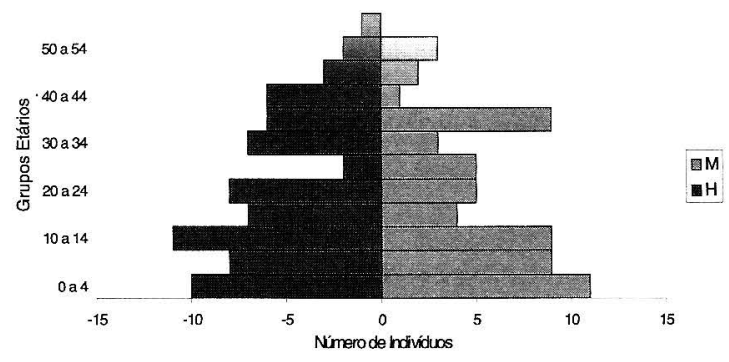

Figura 4 - Pirâmide etária dos Kamaiurá, em grupos qüinqüenais de idade, 2003

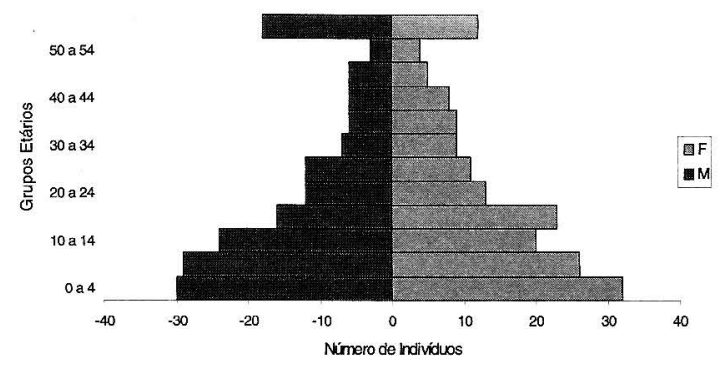

Tabela 4 - Indicadores de fecundidade acumulada das mulheres Kamaiurá, em 1971 e 2003

\begin{tabular}{|c|c|c|c|c|c|c|c|}
\hline Anos & $\begin{array}{c}\text { N. de mulheres } \\
\text { não-solteiras de } \\
15 \text { a } 54 \text { anos }\end{array}$ & $\begin{array}{l}\text { N. de filhos } \\
\text { tidos* }\end{array}$ & $\begin{array}{l}\text { N. de filhos } \\
\text { sobreviventes }\end{array}$ & $\begin{array}{l}\text { N. de filhos } \\
\text { mortos }\end{array}$ & $\begin{array}{l}\text { Média de filhos } \\
\text { tidos" }\end{array}$ & $\begin{array}{l}\text { Média de filhos } \\
\text { sobreviventes }\end{array}$ & $\begin{array}{l}\text { Média de filhos } \\
\text { mortos }\end{array}$ \\
\hline 1971 & 29 & 108 & 70 & 38 & 3,7 & 2,4 & 1,3 \\
\hline 2003 & 65 & 284 & 263 & 21 & 4,3 & 4,0 & 0,3 \\
\hline
\end{tabular}

*exceto os sacrificados por infanticídio.

Fontes: Pesquisas de campo, 1971 e 2003 e arquivos da Usma/Unifesp/EPM.

O inquérito realizado em 1971 já apontava para a intenção dos Kamaiurá em ampliar o tamanho de suas famílias, expressa no número de filhos desejado das pessoas:entrevistadas, de 3,7 e 5,1 filhos, em média, para homens e mulheres, respectivamente. $\mathrm{O}$ aumento da média de filhos por mulher, resultante dessa redefinição intencional do tamanho ideal de família, estaria contribuindo para a expansão das novas gerações. Além disso, o novo padrão de família estaria refletindo, também, a melhoria das condições de saúde e o conseqüente aumento da sobrevivência da população, decorrente das ações médico-sanitárias levadas a efeito nos últimos 35 anos, o que teria garantido a sobrevivência de recém-nascidos e de crianças na primeira infância. 
Essa constatação remete à discussão sobre a complexa relação entre padrões socioculturais e demográficos das sociedades indígenas, que entre os Kamaiurá configura-se claramente na intenção de expandir seu volume populacional e ampliar seu destaque no cenário político do Alto Xingu.

As mudanças culturais e demográficas registradas sugerem que os Kamaiurá se preparam para escolher novos caminhos, resguardando as imagens do passado, mas estabelecendo ligações fortes com o presente e reformulando alguns padrões tradicionais. Sabe-se que a cultura de um povo pode ter larga permanência desde que não perca sua plasticidade e capacidade de orientar o diálogo com os novos tempos e disso extrair um sentido.

Agradecimentos

Aos Kamaiurá pela colaboração com este trabalho.

A pesquisa realizada na aldeia do Ipavu, em 2003, é parte integrante do projeto multidisciplinar Nutrição, Diabetes e Determinantes Socioculturais em Índios Kamaiurá, fruto de convênio entre a Universidade Federal de São Paulo/ Escola Paulista de Medicina (Unifesp/EPM) e a Pontifícia Universidade Católica de São Paulo (PUC-SP), com apoio financeiro da Fundação Nacional de Saúde (Funasa) e da Organização das Nações Unidas para a Educação, a Ciência e a Cultura (Unesco).

\section{Referências Bibliográficas}

COALE, A. J. G HOOVER, E. M. Population Growth and Economic Development in LowIncome Countries. Princeton: Princeton University Press, 1958.

FREEDMAN, R. The Sociology of Human Fertility. England: Basil Blackwell, 1963.

GALVÃO, E. Apontamentos sobre os índios Kamaiurá. In: CARVALHO, J. C. M.; LIMA, P. E. G GALVÃO, E. (Orgs.) Observações Zoológicas e Antropológicas na Região dos Formadores do Xingu. Rio de Janeiro: Imprensa Nacional, 1949. p.31-48.

JUNQUEIRA, C. Os Índios do Ipavu: um estudo sobre a vida do grupo Kamaiurá. 2.ed. São Paulo: Ática, 1978.

MOTTA, J. L. A Epidemia de Sarampo no Xingu. Relatório apresentado à direção do Serviço de Proteção aos Índios, 1954. (Mimeo.)

RIBEIRO, D. Os Índios e a Civilização. Rio de Janeiro: Civilização Brasileira, 1970.

SINGER, P. Dinâmica Populacional e Desenvolvimento. São Paulo: Centro Brasileiro de Análise e Planejamento - Cebrap, 1970. 